\title{
Development of ship sinking frequency model over Subsea Pipeline for Madura Strait using AIS data
}

\author{
Yeyes Mulyadi • Eiichi Kobayashi • \\ Nobukazu Wakabayashi • Trika Pitana • Wahyudi
}

Received: 14 January 2013 / Accepted: 3 July 2013 / Published online: 26 July 2013

(C) World Maritime University 2013

\begin{abstract}
It is important to study the risk posed by heavy shipping traffic to a subsea pipeline located near an industrial port area. In this context, it is essential to estimate the accident frequency in an attempt to eliminate subjectivity in the analysis process. This study proposes a model for estimating the ship sinking frequency over the subsea pipeline in the Madura Strait area. The Madura Strait is one of the busiest shipping lanes in Indonesia. Many ships pass through the fairway in the strait, and many industrial ports have been built in this area. The proposed model is developed based on Fujii's Model, and it uses Automatic Identification System (AIS) data as a ship traffic survey. Ship sinking accidents are considered based on ship-ship collisions over the critical subsea pipeline area. The ship-ship collision locations around the subsea pipeline and the ship traffic distribution models are estimated using AIS data. The causation probability $P c$ is determined based on a synthetics approach using a Bayesian network modified from Det Norske Veritas' and Hänninen's models. The causation probability is estimated by considering factors such as human performance, weather, technical problems, and support. The proposed model is validated by comparing its result with actual accident records for the Madura Strait area. The ratio value of 0.33 is considered to be reasonably agreement (ratio value $\geq 0.2$ ).
\end{abstract}

Keywords Subsea pipeline $\cdot$ Ship sinking frequency $\cdot$ Bayesian network $\cdot$ AIS data $\cdot$ Madura Strait

Electronic supplementary material The online version of this article (doi:10.1007/s13437-013-0049-2) contains supplementary material, which is available to authorized users.

Y. Mulyadi • E. Kobayashi · N. Wakabayashi

Graduate School of Maritime Sciences, Kobe University, 5-1-1, Fukaeminami, Higashinada-ku, Kobe 658-0022, Japan

Y. Mulyadi $(\varangle) \cdot$ T. Pitana $\cdot$ Wahyudi

Institut Teknologi Sepuluh Nopember (ITS), Surabaya, Indonesia

e-mail: 084w754w@stu.kobe-u.ac.jp

T. Pitana $\cdot$ Wahyudi

Faculty of Marine Technology, Campus ITS, Keputih, Sukolilo, Surabaya 60111, Indonesia 


\section{Introduction}

Natural gas has emerged as an important commodity in the ASEAN (Association of Southeast Asian Nations) region from the viewpoint of economic policies, energy diversification, and mitigation of climate change. In the last decade, many offshore natural gas fields have been discovered in the ASEAN region. To reduce transportation distances and to minimize costs, natural gas is transported by subsea pipelines. Therefore, domestic and cross-border subsea pipeline networks in the ASEAN region are being developed rapidly to provide the necessary infrastructure for the more widespread utilization of natural gas (APERC 2000).

The Madura Strait is one of the busiest shipping lanes in Indonesia. It lies between Java Island and Madura Island. Sea depth for shipping lane is around 9.5 to $14 \mathrm{~m}$. A large number of cargo ships, passenger ships, tanker ships, and service ships pass through the fairway in the strait. Furthermore, many ports such as the Tanjung Perak Port, Cement Port, Maspion Port, Gresik Port, Smelting Port, and Petrokimia Port have been built in the Madura Strait area.

A subsea pipeline network is also located in the Madura Strait area. The construction of this pipeline was completed in 2008. This pipeline transports natural gas from gas platforms in the Madura Block to Onshore Processing Facilities (OPF) in the Gresik Region on Java Island. The pipeline's route is along a shipping lane in the Madura Strait area from Kilometer Point 35 to OPF (KP35-OPF) as shown in Fig. 1. The North side of the Madura Strait area, close to KP35, is defined as the entry and exit gate of the shipping lane. The pipeline has an outer diameter of 16 in., and it is used to transport 90-200 million standard cubic feet of natural gas per day. For the safety of the subsea pipeline, the pipeline is buried in around $2 \mathrm{~m}$ of soft clay under

Fig. 1 Subsea pipeline route along shipping lane in Madura Strait area

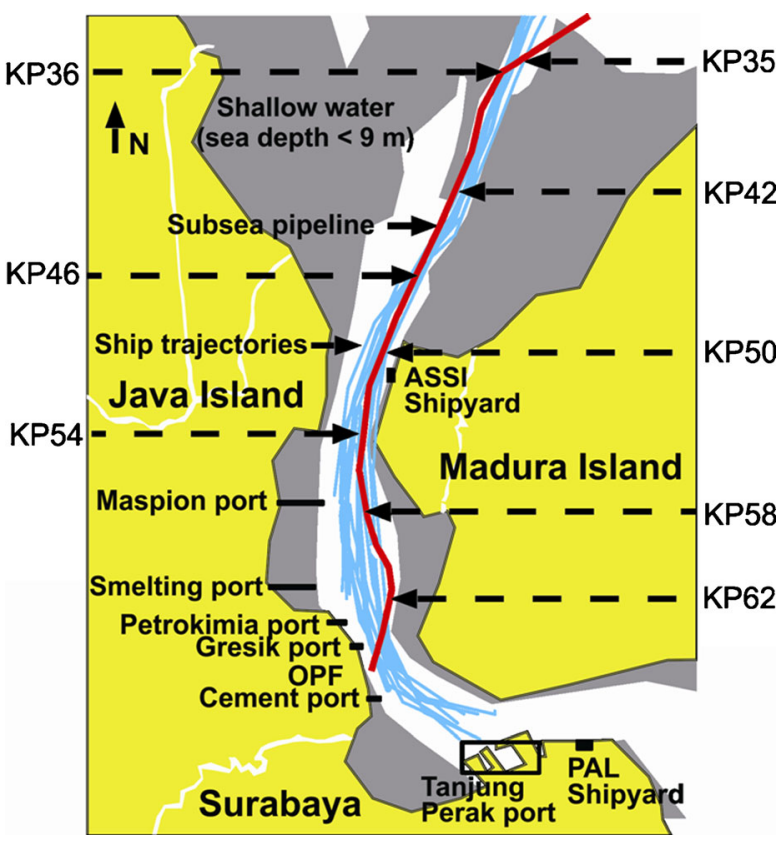


the seabed, and navigation buoys and a navigation map have been developed (Mulyadi et al. 2011).

The subsea pipelines in the Madura Strait area are seriously threatened by the heavy shipping traffic through the strait. The safety of the subsea pipeline is a critical issue because the pipeline is likely to be exposed to damage owing to external factors such as dragging anchors, sinking ships, and other objects falling to the sea floor.

This study proposes a model for estimating the frequency of ships sinking over the subsea pipeline in the Madura Strait area. This model is developed based on the concept introduced by Fujii, and it uses Automatic Identification System (AIS) data for the shipping traffic survey. The proposed model deals with the following issues:

1. A scenario in which a ship sinking accident occurs in the Madura Strait area is considered for ship--ship collision over the critical subsea pipeline area. After a ship-ship collision, ships may sink and damage the pipeline.

2. The shipping traffic distributions in the Madura Strait fairway are estimated using AIS data.

\section{Modeling}

\subsection{Modeling of ship sinking frequency due to collision}

Recently, the frequency of ship collisions has been estimated using statistical and mathematical methods. Statistical methods provide realistic figures, but they are difficult to use for future predictions because the situation may differ from today. Mathematic models represent the behavior of real phenomena or objects in mathematical terms, and they can be applied to predict the frequency of ship collisions in the future (Pedersen 2010). Fujii et al. developed a mathematical approach that is commonly used to estimate the ship collision frequency. Several models that have been developed by some researchers are presented in "Chapter 2.2.1." The Fujii's model is expressed as follows (Fujii et al. 1974):

$$
N=N a \cdot P c
$$

where $N$ is the expected number of ship collisions; $N a$, the number of ship collision candidates; and $P c$, the causation probability defined as the probability of failing to avoid a collision when on a collision course.

This study proposes a model to estimate the ship sinking frequency over the subsea pipeline based on the concept introduced by Fujii. The scenario of a ship sinking and damaging the subsea pipeline is considered based on ship-ship collision when the ships are moving over the critical subsea pipeline area. After the ships collide, extensive damage to their hulls may cause them to sink in the critical subsea pipeline area (Mulyadi et al. 2011).

According to this scenario, the proposed model for estimating the ship sinking frequency due to ship-ship collision in the critical subsea pipeline area for subject ship belonging to class $i$ in zone $z, N s_{i z}$, is expressed as follows:

$$
N s_{i z}=N a_{i z} \cdot P c \cdot P_{f}
$$


where $\mathrm{Na}_{i z}$, the number of ship-ship collision candidates for subject ship belonging to class $i$ in zone $z$ if ships are on a collision course; $P c$, the causation probability defined as the probability of failing to avoid a collision when on a collision course; and $P_{f}$, the conditional probability of a ship foundering after ship-ship collision.

\subsection{Modeling of ship-ship collision over subsea pipeline area}

Based on the historical data gathered by Tanjung Perak Port Authority related with ship-ship collisions in the Madura Strait, there are 18 collisions in 1997-2011, 94.4\% of the cases are head-on collisions, and 5.6\% are crossing collisions. It can be clearly seen that the main cause of the collisions are head-on type. Therefore, in this study, the $\mathrm{Na}$ model is developed only for head-on ship-ship collisions. In general, the layouts of the subsea pipeline in the Madura Strait can be categorized into two types: crossing and parallel subsea pipelines. Figures 2 and 3 respectively show a meeting ship encountering a subject ship over crossing and parallel subsea pipelines in a fairway. The subject and meeting ship pass through fairways 1 and 2 in a subsea pipeline zone $z$. Fairways 1 and 2 respectively have lateral probability distribution of the ship traffic, $f_{z}^{(1)}(y)$ and $f_{z}^{(2)}(y)$. A length of critical segment for the subsea pipeline area in zone $z$ is $L_{c z}$. A width of the subject ship belonging to class $i$ in fairway 1 is $B_{i}^{(1)}$. A width of the meeting ship belonging to class $j$ in fairway 2 is $B_{j}^{(2)}$. The collision diameter, $B_{i}^{(1)}+B_{j}^{(2)}$, is approached based on the concept introduced by Kristiansen (2005) and COWI (2008). The differences between the ship course of the meeting and the subject ship for a head-on collision are around $180 \pm 10^{\circ}$.

\subsubsection{Number of ship-ship collision candidates}

The number of ship-ship collision candidates $\mathrm{Na}$ is defined as the number of ship pairs being on a collision course. In other words, ship-ship collision will occur if no corrective action or maneuvering is performed.

Pedersen (2010) developed a model to estimate $\mathrm{Na}$ using several parameters such as the traffic flow, ship speed, and static collision diameter $D_{i j}$ as a critical distance in an encounter situation. Talavera et al. (2013) modified the model of traffic distribution functions in Pedersen's model by using Dempster-Shafer theory. This method is

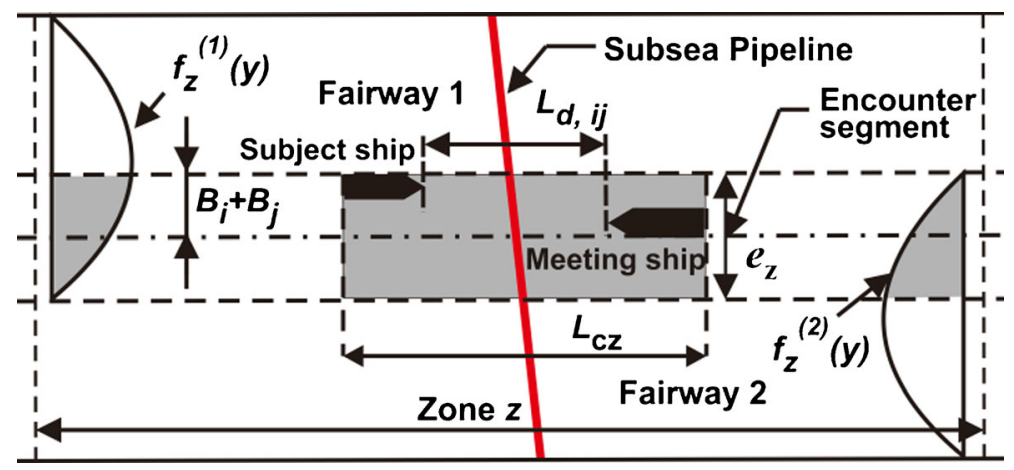

Fig. 2 Ship-ship encounter in critical crossing subsea pipeline area 


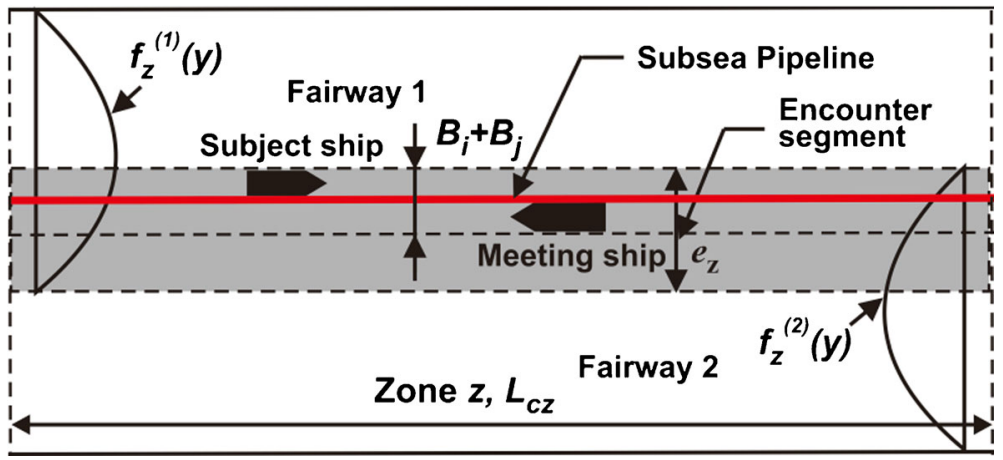

Fig. 3 Ship-ship encounter in critical parallel subsea pipeline area

proposed for quantification and propagation the uncertainty originated from the variability of trajectories. Montewka et al. (2010) modified Pedersen's $\mathrm{Na}$ model. In their model, $D_{i j}$ was replaced with the minimum distance to collision (MDTC) estimated using an experimental ship model. In other words, ship maneuverability was represented by MDTC. However, MDTC results are valid only for a ship sailing at full speed and provided that the ships have started to take evasive action simultaneously (Goerlandt and Kujala 2011). In further developing of the MDTC, Montewka et al. (2012) proposed the $\mathrm{Na}$ model using the MDTC value and causation factor for three types of meeting: crossing, head-on, and overtaking. To determine the MDTC value, the parameters of ship types, courses, intersection angles, relative bearing, and speed are considered in the simulation. Another approach to estimate the $\mathrm{Na}$ was proposed by Goerlandt and Kujala (2011) using dynamic traffic simulation model. This method uses a micro-simulation in the time domain for movement of each individual ship operating in specific area. Friis-Hansen et al. (2009) proposed a $\mathrm{Na}$ model that depends on the segment length, geometry probability, traffic flow, and ship speed. In this model, the geometry probability is dependent on the lateral ship traffic distribution, which is typically defined by a normal distribution.

In this study, we develop $N a$ model that is inspired by Pedersen's and FriisHansen's model and that follows the concept introduced in Fujii's model. FriisHansen's model itself is based on a concept similar to Pedersen's model. Both models define the characteristics of ships approaching each other and ship-ship collision candidates geometrically. However, in Pedersen's model, the geometrical collision probability is not divided into an independent probability. In Friis-Hansen's model, on the other hand, the geometrical collision probability is divided into an independent probability. Therefore, this model is easier to use in practice.

In Pedersen's ship-ship collision model, when two ships, $i$ and $j$, approach a segment of the fairway, they have a relative speed $V_{i j}$ given by the following equation.

$$
V_{i j}=V_{i}+V_{j}
$$

The probability of the ships passing over a encounter segment of a subsea pipeline area $P_{e z}^{(\alpha)}$ is calculated by integrating the lateral probability distribution of ship traffic over the subsea pipeline area in a specific range of a ship-ship encounter segment, $e_{z}$ as seen in Figs. 2 and 3. $P_{e z}{ }^{(1)}$ represents the probability of subject ships passing over a encounter segment of a subsea pipeline area in fairway 1 in zone $z$ and $P_{e z}^{(2)}$, the 
probability of meeting ships passing over a encounter segment of a subsea pipeline area in fairway 2 in zone $z$. They are expressed as follows.

$$
\begin{aligned}
& P_{e z}^{(1)}=\int_{e_{z}} f_{z}^{(1)}(y) \\
& P_{e z}^{(2)}=\int_{e_{z}} f_{z}^{(2)}(y)
\end{aligned}
$$

where $f_{z}^{(1)}(y)$ is the lateral probability distribution of the ship traffic over the subsea pipeline area for subject ships in fairway 1 in zone $z$ and $f_{z}^{(2)}(y)$, the lateral probability distribution of the ship traffic over the subsea pipeline area for meeting ships in fairway 2 in zone $z$. The range of $e_{z}$ represents the width of the ship-ship encounter segment in zone $z$.

The probability of a subject ship colliding with a meeting ship in the critical segment of the subsea pipeline area in a meeting situation if no evasive action or maneuver is performed is expressed as a geometrical collision probability in zone $z P_{g z}$. $P_{g z}$ is obtained by multiplying the probability of a ship being in the critical segment of the subsea pipeline area in zone $z P_{l z}$, and the probability of a ship being in the critical distance side-by-side in zone $z P_{b z} . P_{g z}$ is expressed as follows:

$$
P_{g z}=P_{l z} P_{b z}=\left(\frac{L_{c z}}{L_{t}}\right)\left(\frac{B_{i}^{(1)}+B_{j}^{(2)}}{e_{z}}\right)
$$

where $L_{c z}$ is the length of critical segment for the subsea pipeline area in zone $z ; L_{t}$, the length of the all segments; $B_{i}^{(1)}$, the width of the subject ship belonging to class $i$ in fairway $1 ; B_{j}{ }^{(2)}$, the width of the meeting ship belonging to class $j$ in fairway 2 ; and $e_{z}$, the width of the ship-ship encounter segment in zone $z$.

The number of subject ships belonging to class $i$ in fairway 1 on a collision course in the critical segment of the subsea pipeline area with one meeting ship belonging to class $j$ in fairway 2 during unit time $\Delta T$ is expressed as follows:

$$
\frac{Q_{i}^{(1)}}{V_{i}^{(1)}}\left(V_{i j} \Delta T\right) P_{e z}^{(1)} P_{g z}
$$

where $Q_{i}^{(1)}$ is the number of subject ships belonging to class $i$ in fairway 1 per unit time and $V_{i}^{(1)}$, the speed of the subject ship belonging to class $i$ in fairway 1 .

The number of meeting ships belonging to class $j$ in the critical segment of the subsea pipeline area is expressed as follows:

$$
\frac{Q_{j}^{(2)}}{V_{j}^{(2)}} L_{c z} P_{e z}^{(2)}
$$

where $Q_{j}^{(2)}$ is the number of meeting ships belonging to class $j$ in fairway 2 per unit time and $V_{j}^{(2)}$, the speed of the meeting ship belonging to class $j$ in fairway 2 . 
The number of ship-ship collision candidates is obtained by multiplying Eqs. 7 and 8 and summing up the different ship classes in each critical segment and zone. Therefore, the number of head-on ship-ship collision candidates in the critical segment of the subsea pipeline area for subject ship belonging to class $i$ in zone $z$, $N a_{i z}$, is expressed as follows:

$$
N a_{i z}=L_{c z} \sum_{i, j} \frac{V_{i}^{(1)}+V_{j}^{(2)}}{V_{i}^{(1)} V_{j}^{(2)}} Q_{i}^{(1)} Q_{j}^{(2)} P_{e z}^{(1)} P_{e z}^{(2)} P_{g z} \Delta T
$$

\subsubsection{Length of critical segment for subsea pipeline area}

a. Crossing subsea pipeline

Based on the ship-ship encounter scenario over a crossing subsea pipeline as shown in Fig. 2, $N a_{i z}$ is considered using the following criterion: whether a ship-ship encounter occurs in the critical segment of the subsea pipeline area.

In this proposed model, the length of critical segment for the crossing subsea pipeline area as in Eq. 9, $L_{c z}$, is approached based on a concept proposed by Weng et al. (2012). In Weng's model, a ship-ship encounter is defined as a critical situation in which the subject ship is expected to enter the meeting ship's domain in the next time interval $\Delta t$. The distance to the meeting ship's domain $j$ is approximately three times the ship length. Thus, the encounter distance $L_{d, i j}$ for subject ship $i$ encountering meeting ship $j$ is expressed as follows:

$$
L_{d, i j}=\left(V_{i}^{(1)}+V_{j}^{(2)}\right) \cdot \Delta t+3 L_{j}^{(2)}
$$

where $\Delta t$ is the critical time interval of the subject ship that is expected to enter the meeting ship's domain. $L_{j}^{(2)}$ is the length overall (LOA) of the meeting ship belonging to class $j$ in fairway 2 .

Hence, the length of critical segment for the crossing subsea pipeline area in zone $z$ as shown in Fig. 2, $L_{c z}$, is expressed as follows:

$$
L_{c z}=L_{i}^{(1)}+L_{j}^{(2)}+L_{d, i j}
$$

where $L_{i}^{(1)}$ is the LOA of the subject ship of class $i$ in fairway 1 and $L_{j}^{(2)}$, that of the meeting ship of class $j$ in fairway 2 .

b. Parallel subsea pipeline

The length of critical segment for the parallel subsea pipeline area in zone $\mathrm{z}$ as shown in Fig. 3, $L_{c z}$, is estimated based on an effective length of the subsea pipeline in zone $\mathrm{z}$ that the pipeline is likely to be exposed to damage owing to a ship sinking.

\subsubsection{Causation probability}

Recently, the causation probability $P c$ has been estimated using two approaches: scenario approach and synthetics approach (Kujala et al. 2009). The scenario approach is calculated based on the statistics of available historical accident data. Pedersen and 
Zhang (1999) argued that the scenario approach can be calculated from accident data at various locations and transformed to the analyzed location. The synthetics approach is calculated based on specific error situation analysis that can occur on ships. In this approach, the probability of error situations can be estimated using some methods such as Bayesian networks or fault tree analysis (Hänninen and Kujala 2012).

In this study, $P c$ is estimated based on the synthetics approach using a Bayesian network. The model Bayesian network is developed by modifying network fragments developed by Det Norske Veritas DNV (2003) and Hänninen and Kujala (2012). The Bayesian network should reflect the specific characteristics of a studied location, which in this case is the Madura Strait area. Based on collision records in the Madura Strait area from Tanjung Perak Port Authority, on total of 18 accidents in 1997-2011, all ship-ship collisions are caused by ships losing control. The major factors contributing to ships losing control based on the accident record were weather conditions, navigational aid detection, human performance, the pilot guiding the ships, communication with other ships, and steering failure. The $P c$ obtained using a Bayesian network model for practical application in the Madura Strait area is expressed as shown in Fig. 4.

\subsubsection{Probability of ship foundering after collision}

A ship may undergo minor or major structural failures after collision. If a collision results in major structural failure, the ship may founder to the seabed. Recently, the probability of a ship foundering after collision has been estimated by two methods: analytical method and statistical method. As an analytical method, Otto et al. (2002) developed a model by integrating the joint probability of the damage density function of the length, depth, and height of damage from the collision impact. As a statistical method, Fowler and Sorgård (2000) estimated the probability of a ship foundering based on Lloyd's Maritime Information Services data.

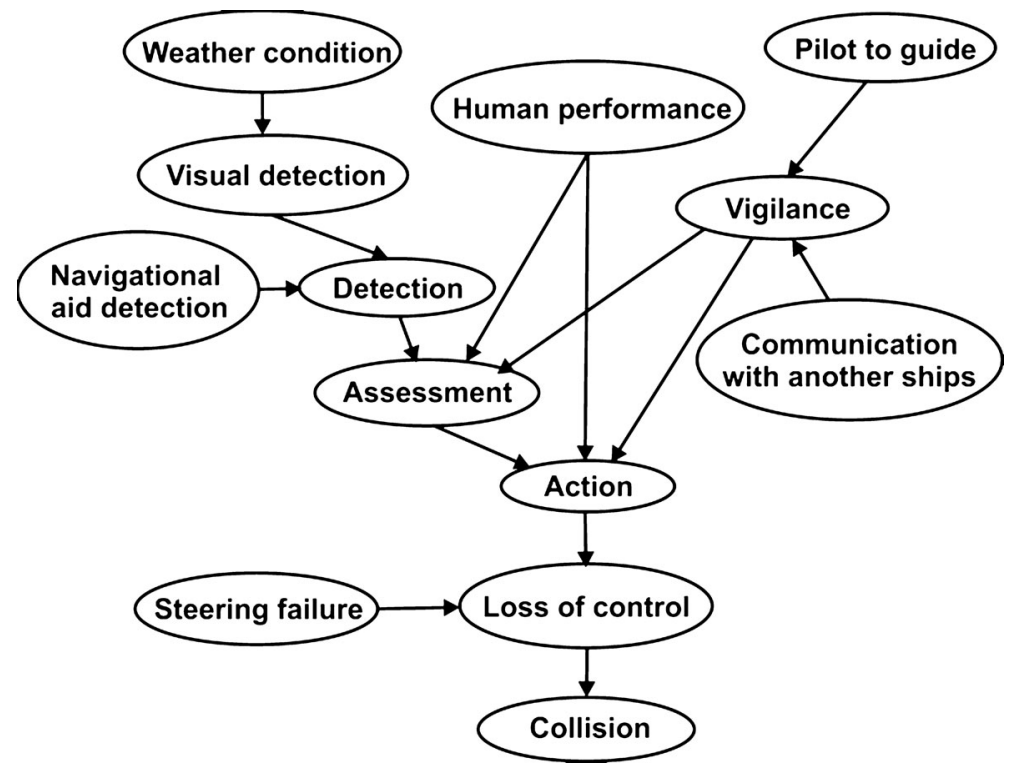

Fig. 4 Bayesian network model of causation probability for ship-ship collision in Madura Strait area 
In this study, the conditional probability of a ship foundering after collision is determined based on a statistical method. This method is reasonable for estimating the probability of a ship foundering using general ship data and is easy to use in practice (Fowler and Sorgård 2000). The conditional probability of a ship foundering after collision $P_{f}$ is expressed as follows:

$$
P_{f}=\frac{N_{a f}}{N_{a c}}
$$

where $N_{a f}$ is the number of actual ships foundering after collision in the fairway and $N_{a c}$, the number of actual ship collisions in the fairway. The data used in the analysis may contribute uncertainty because the actual data in specific area may have limited number of accidents.

\subsection{Usage of AIS for marine traffic survey}

The International Maritime Organization (IMO) mandated the use of AIS navigation for merchant ships at the SOLAS convention in 2000 (IMO 2002). Specifically, a regulation in SOLAS chapter V requires AIS to be fitted in ships of 300 gross tonnage (GT) and above engaged in international voyages, ships of 500 GT and above not engaged in international voyages, and all passenger ships irrespective of size. The AIS equipment transmits ship traffic data to other ships or land-based AIS receivers.

The AIS data can be used to survey the ship trajectories and to analyze the ship traffic distributions. The data do not fully reflect the existing traffic conditions in certain location because AIS equipment is not installed in all ships. However, the AIS data are still reliable and helpful to analyze the ship traffic distributions. Besides, the AIS data do not provide full information about ships. The data of ship's principal dimensions are not included in the AIS data. Therefore, external resources are required to obtain these data.

In this study, both AIS and GIS data are combined for estimating the lateral probability distribution of the ship traffic model around the subsea pipeline area. Figure 5 shows the usage of AIS data for the ship traffic model in the subsea pipeline area.

\section{Analysis and results}

\subsection{Ship category using AIS data}

The ship traffic data in the Madura Strait area is obtained from an AIS receiver that recorded data in 2008-2011. The AIS receiver was installed at the Institut Teknologi

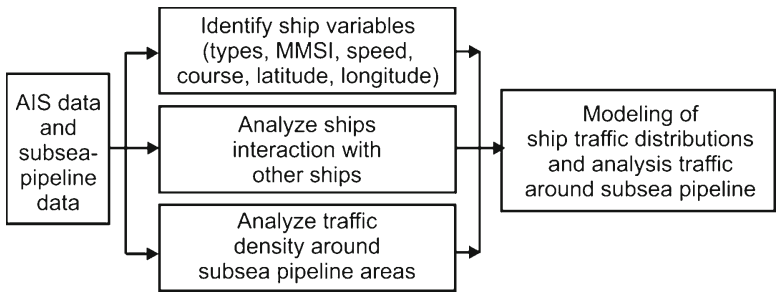

Fig. 5 Usage of AIS data for ship traffic distribution model and analysis around subsea pipeline areas 
Sepuluh Nopember, Surabaya, Indonesia, in cooperation with Kobe University, Japan. The number of ships per year in the Madura Strait area as obtained from the AIS data is 29,830, 30,934, 28,918, and 31,420 in 2008, 2009, 2010, and 2011, respectively.

Figure 6 shows the distribution of the different types of all ships per year as obtained from the AIS data in the Madura Strait area. The several types of ships such as bulk carrier ships, general cargo ships, container ships, passenger ships, tanker ships, tugboats and supply ships, and navy/patrol ships pass through the Madura Strait area. The general cargo, container, and tanker ship respectively have large number of percentages by $38 \%, 20 \%$, and $15 \%$.

Figure 7 shows the distribution of the average number of different types of ships per day as obtained from the AIS data in the Madura Strait area. Bulk Carrier (Handysize), General Cargo (small and medium), Container (small and feeder), and Tanker (Medium Range) have large number per day to pass through in the Madura strait.

Data for the dimensions of the ships that pass through the Madura Strait area are presented as shown in Table 1. These data show ship classes, average of LOA, and average of width (B) in meter unit.

\subsection{Ship collision location around subsea pipeline}

Ship-ship collision locations around the subsea pipeline are determined based on the ship-ship encounter segment locations that are estimated based on the ship traffic distributions using AIS data. According to the ship traffic distribution analysis in the Madura Strait area, there are two hazardous locations from the viewpoint of the high risk of ship-ship collisions around the subsea pipeline: near KP35-KP36 (crossing pipeline) and near KP42-KP46 (crossing pipeline), as shown in Fig. 8. In these locations, the subject and meeting ships are predicted to meet in an encounter segment around subsea pipeline area. In another crossing subsea pipeline location, KP64-OPF, the pipeline is buried to a depth of $19 \mathrm{~m}$ beneath the seabed using the horizontal directional drilling method, and therefore, it is well protected.

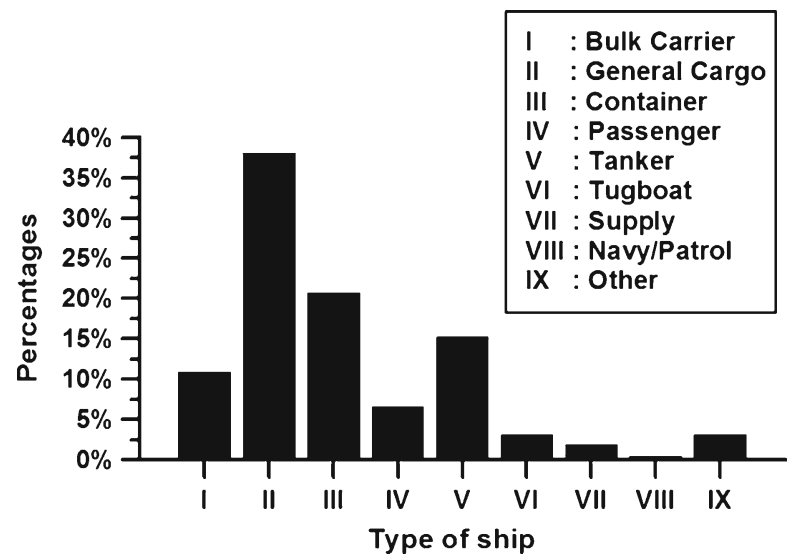

Fig. 6 Distribution of different types of ships in Madura Strait area (expressed as a percentages) 


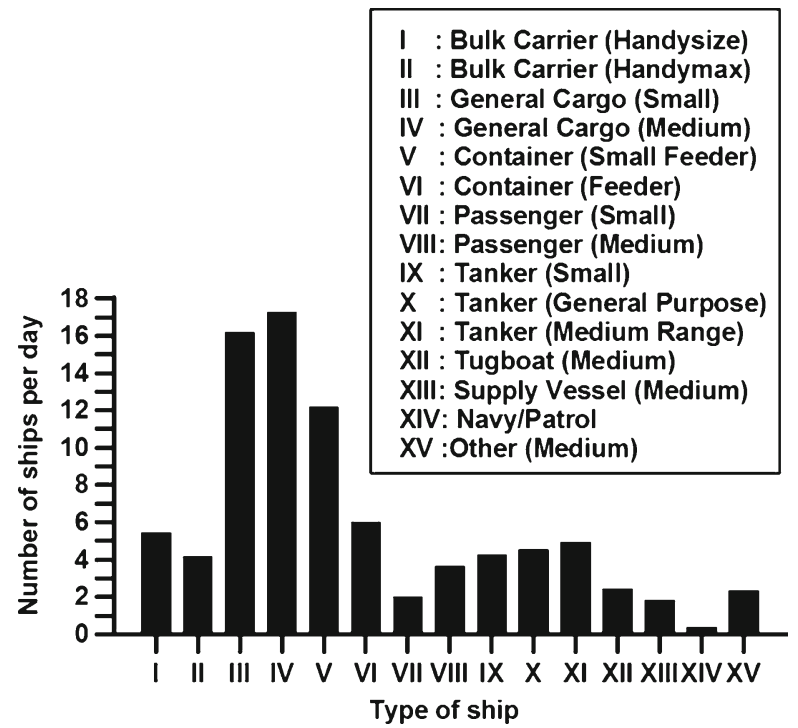

Fig. 7 Distribution of average number of different types of ships per day in Madura Strait area

\subsection{Ship traffic distribution modeling}

The lateral probability distribution for arrival and departure from harbor in the Madura strait respectively are defined as southbound and northbound lateral traffic distribution. The modeling of the lateral probability distributions are approximated by continuous distributions based on the ship tracks in selected locations. The selection of the fit distribution models are validated by Kolmogorov-Smirnov test.

Table 1 Dimensions of different types of ships in Madura Strait

\begin{tabular}{lll}
\hline Ship classes & Average of LOA $(\mathrm{m})$ & Average of width (B) (m) \\
\hline Bulk carrier (handysize) & 170 & 27 \\
Bulk carrier (handymax) & 190 & 30 \\
General cargo (small) & 100 & 17 \\
General cargo (medium) & 148 & 22 \\
Container (small feeder) & 150 & 23 \\
Container (feeder) & 200 & 30 \\
Passenger (small) & 65 & 16 \\
Passenger (medium) & 116 & 20 \\
Tanker (small) & 97 & 16 \\
Tanker (general purpose) & 160 & 25 \\
Tanker (medium-range) & 182 & 27 \\
Tugboat (medium) & 35 & 9 \\
Supply (medium) & 66 & 11 \\
Navy/patrol (medium) & 92 & 13 \\
Other (medium) & 90 & 14 \\
\hline
\end{tabular}




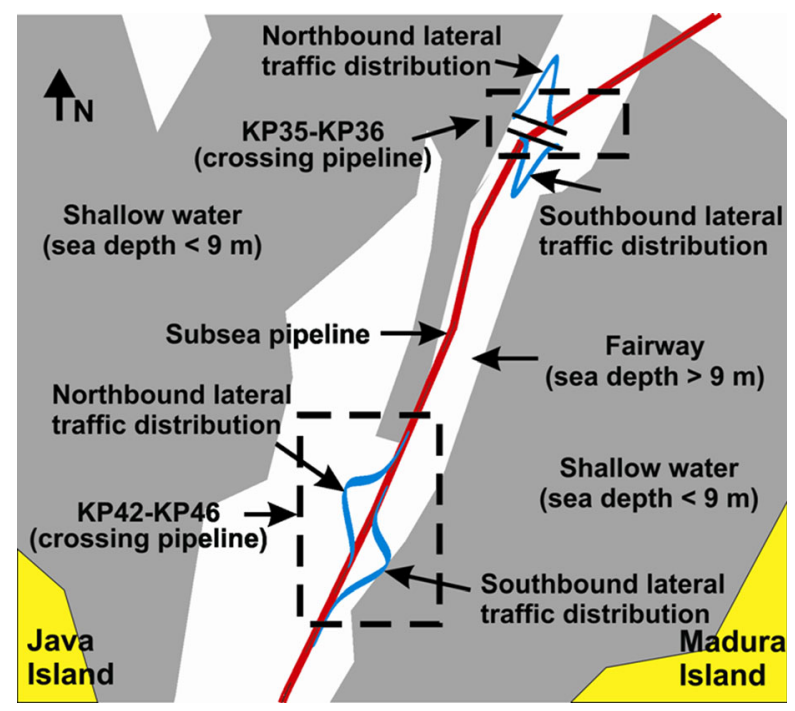

Fig. 8 Hazardous locations around subsea pipeline in Madura Strait area

The results of the southbound and northbound lateral traffic distribution model, and also the encounter segment for KP35-KP36 and KP42-KP46 are respectively shown in Figs. 9 and 10. Furthermore, the result of the lateral probability distributions for southbound and northbound are used to estimate the $\mathrm{e}_{\mathrm{z}}, P_{e z}^{(1)}$ and $P_{e z}^{(2)}$.

\subsection{Causation probability in Madura Strait}

The causation probability $P c$ of ship-ship collisions over the subsea pipeline in the Madura Strait area is determined by using a Bayesian network, as shown in Fig. 4. The values of the variables in the Bayesian network are estimated using data obtained from the Tanjung Perak Port Authority and external data related to the subject.

The data from the Tanjung Perak Meteorology, Climatology, and Geophysics Institute in 2005-2010 are used to estimate the probability of weather conditions. The probability of weather condition is presented in Table A1 of Appendix A.

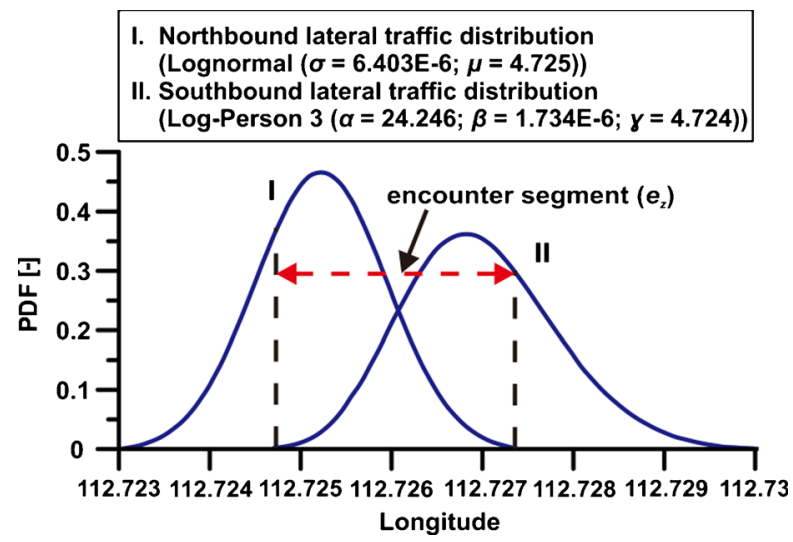

Fig. 9 Lateral distribution probability of ship traffic for KP35-KP36 


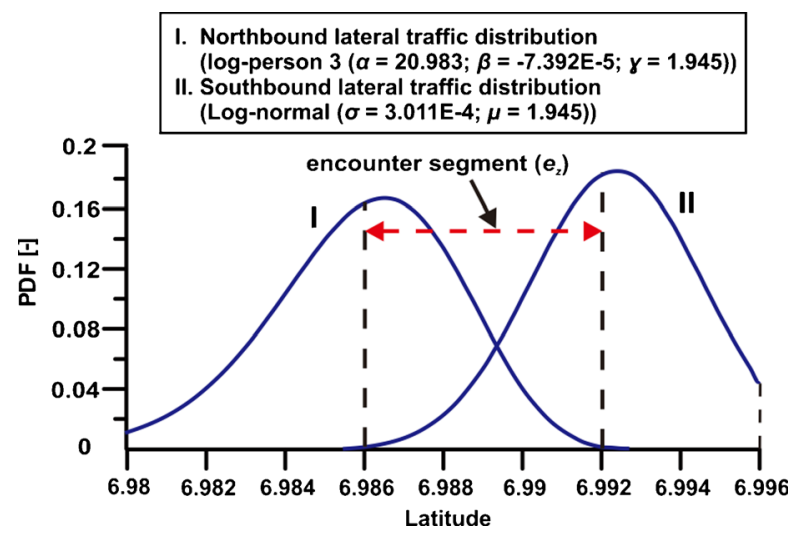

Fig. 10 Lateral distribution probability of ship traffic for KP42-KP46

The probability of visual detection or visibility is a conditional probability that is estimated based on the probability of the weather conditions. Good weather conditions are equivalent to good visibility $(>1 \mathrm{~nm})$. Thus, the logical conditional probability of visibility is 1 in good weather conditions. Storm/heavy rain conditions are equivalent to poor visibility $(<1 \mathrm{~nm})$. Thus, the logical conditional probability of visibility is reduced by $25 \%$ in storm/heavy rain conditions (DNV 2003). The probability of visual detection is presented in Table A2 of Appendix A.

The probability of navigational aid detection describes the possibility of radar and AIS systems in functioning and being used to detect other ships. The value of the probability of radar and AIS detection is estimated based on data from the Tanjung Perak Port Authority. The probability of navigational aid detection is presented in Table A3 of Appendix A.

The data of port pilots guiding ships to exit and enter in the Madura Strait area are estimated using data from Tanjung Perak Port Authority in 2005 to 2010. The probability of pilot to guide ships in the Madura Strait area is presented in Table A4 of Appendix A.

The probability of communication with other ships indicates whether the Officer On Watch (OOW) receives a warning call from other ships on a collision course, e.g., on VHF. Based on data obtained from the Tanjung Perak Port Authority in 2005-2010, the probability of communication with other ships is presented in Table A5 of Appendix A.

The probability of vigilance is a conditional probability based on the probability of an on-board port pilot and probability of communication with other ships. The onboard port pilot and communication with other ships provide internal and external vigilance that can warn the OOW of dangerous situations (DNV 2003). The logical conditional probability of vigilance is presented in Table A6 of Appendix A.

The probability of human performance is adapted from the result of Harahap et al.'s study of human performance for ships officer in the Madura Strait area (Harahap 2011). The probability of human performance for ship-ship collision candidate in the Madura Strait area is presented in Table A7 of Appendix A.

The probability of ship steering failure in the Madura Strait area is estimated based on data from the Tanjung Perak Port Authority in 2005-2010. In that period, there were 174,927 ships passing in the Madura Strait, and six of them experienced steering failure system. The probability of ship steering failure is presented in Table A8 of Appendix A. 
Thus, the causation probability of failing to avoid a collision $P c$ in the Madura Strait area is calculated to be $1.08 \times 10-4$ using the Bayesian network.

\subsection{Ship sinking frequency over subsea pipeline}

The ship sinking frequency over the subsea pipeline for subject ship belonging to class $i$ in zone $z, N s_{i z}$, is estimated using Eq. 2. The number of the head-on ship-ship collision candidates in the critical segment of the subsea pipeline area for subject ship belonging to class $i$ in zone $\mathrm{z}, N a_{i z}$, is estimated using Eq. 9. The value of the causation probability of failing to avoid a collision $P c$ using Bayesian network model is $1.08 \times 10^{-4}$. The average shipping traffic for each ship class per day is estimated based on the AIS data, as shown in Fig. 7. For head-on ship-ship collisions, the length of the critical segment for the crossing subsea pipeline area $L_{c z}$ is calculated based on Eq. 11. The ship speed passing through in the Madura Strait is average 6 knots. Thus, the value of $\Delta t$ is considered as 3 min for a low ship speed (Weng et al. 2012). The lateral probability distribution function $f_{z}^{(\alpha=1,2)}(y)$ and the range of the ship-ship encounter segment $e_{z}$ as shown in Figs. 9 and 10 for location of KP35-KP36 and KP42-KP46. The length and width of the ships in the Madura Strait area is presented in Table 1. The conditional probability of a ship foundering after collision $P_{f}$ is estimated based on Eq. 12 using historical accident data for the Madura Strait area. Based on data from Tanjung Perak Port Authority, there are 18 ship-ship collision accidents and only six ships foundering after collision in 1997-2011. Thus, $P_{f}$ in the Madura Strait area is 0.34 . Many local ships

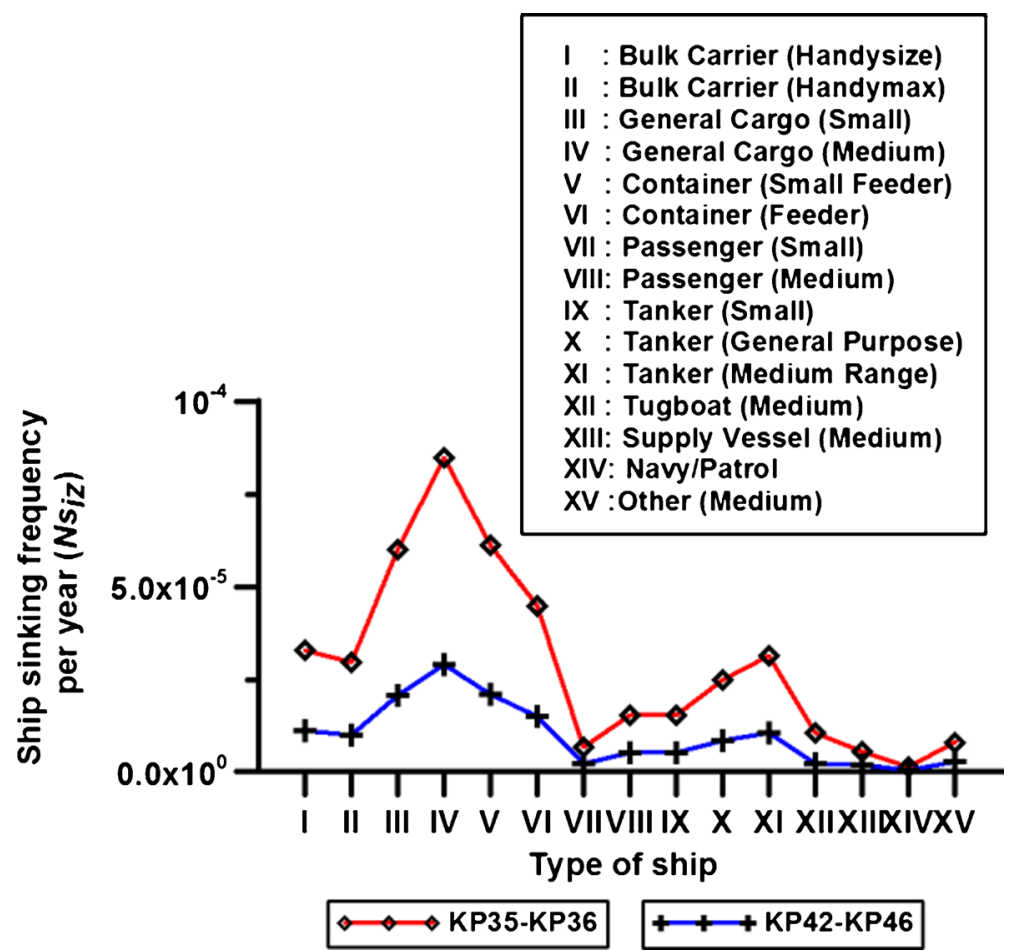

Fig. 11 Ship sinking frequency per year for KP35-KP36 and KP42-KP46 
belonging Indonesia flag are old ships that are maintained below standard (Trans Asia 2009). Implementation of SOLAS regulation should be maintained continuously to ensure the ship safety. Based on ship data in the Madura Strait gathered using AIS combined with ship data from Biro Klasifikasi Indonesia, in January-June 2009, there are $30 \%$ of ships having age between $25-35$ years, and $15 \%$ are $35-40$ years.

The results of the ship sinking frequency over the subsea pipeline in the Madura Strait area, $N s_{i z}$, are shown in Fig. 11 for all ship classes $i$ in the location of KP35KP36 and KP42-KP46. The frequency ranking is assessed based on the recommended practice of DNV (2010)). Figure 11 shows that KP35-KP36 has higher ship sinking frequency than KP42-KP46. These are reasonable results because KP35KP36 has narrower fairway than KP42-KP46. In general results, several ship types such as Bulk Carrier (Handysize), General Cargo (Small), General Cargo (Medium), Container (Small Feeder), Container (Feeder), and Tanker (Medium Range) have higher risk than other ships (Bulk Carrier, Passenger ship, Tugboat, etc.) in the Madura Strait. Furthermore, for KP35-KP36, $N s_{i z}$ for General Cargo (Small), General Cargo (Medium), and Container (Small Feeder) classes are within the lowfrequency ranking, level $2\left(10^{-4} \geq \times>10^{-5}\right)$. For KP42-KP46, $N s_{i z}$ for all ship classes are within the very low-frequency ranking, level $1\left(<10^{-5}\right)$.

\subsection{Validation}

The subsea gas pipeline is a new structure in the Madura Strait area. Its construction was completed in 2008 . The causation probability of failing to avoid a collision $P c$, as described in the previous section, is estimated to be $1.08 \times 10^{-4}$. The numbers of ships sinking using proposed model in 1997-2011 are estimated to be two ships whereas the actual numbers of ships sinking are six ships based on the data from Tanjung Perak Port Authority. Thus, the results of the comparison between number of ships sinking using proposed model and actual data accidents in 1997-2011 are estimated to be 0.33 . This ratio value is considered to be reasonably agreement (ratio $\geq 0.2$ (Fowler and Sorgård 2000)).

A reason for this difference is that the proposed model uses assumption that all traffic intensity is spread uniformly over all day. This is not quite the same situation in actual condition that traffic intensity can increase during in particular period of the day. When the traffic intensity increases significantly, the probability of encounter is higher than in assumption in the proposed model. Another reason, the network variable to estimate $P c$ is quite simple. In the future work, it is important to elaborate the network variable of the Bayesian network to improve the estimation of $P c$.

\section{Conclusion}

This study proposes a model for estimating the ship sinking frequency over a subsea pipeline in the Madura Strait area. The following conclusions are derived from this study:

1. This study proposes a model for estimating the ship sinking frequency due to ship-ship collisions over a subsea pipeline in the Madura Strait area based on Fujii's model. 
2. AIS data is used for estimating a hazard location around the subsea pipeline, probability of the ships passing over a encounter segment of a subsea pipeline $P_{e z}{ }^{(\alpha)}$ and geometrical collision probability $P_{g z}$.

3. The length of critical segment for the crossing subsea pipeline area in zone $z L_{c z}$ is determined based on the concept proposed by Weng et al. In Weng's method, ship conflict is defined as a critical situation in which a ship is expected to enter another ship's domain in the next time interval $(\Delta t=3 \mathrm{~min})$ at low speed. The length of a ship's domain is approximately three times its length.

4. The method for estimating the causation probability of failing to avoid a collision $P c$ is based on a synthetics approach using a Bayesian network. The model network of the Bayesian network in the Madura Strait area is developed based on a modification of DNV's and Hänninen's models. Most ship collisions in the Madura Strait area are caused by ships losing control. Based on historical accident data, the main contributing factors considered in the Bayesian network for the Madura Strait area are weather, human performance, pilot vigilance, communication, and navigation. The causation probability of ship-ship collisions in the Madura Strait area $P c$ is calculated to be $1.08 \times 10^{-4}$.

5. For KP35-KP36, the ship sinking frequency for General Cargo (Small), General Cargo (Medium), and Container (Small Feeder) classes over the subsea pipeline per year is determined to fall into the low-frequency ranking, level 2 $\left(10^{-4} \geq x>10^{-5}\right)$. For KP42-KP46, the ship sinking frequency for all ship classes over the subsea pipeline per year is determined to fall into the very low-frequency ranking, level $1\left(<10^{-5}\right)$. The frequency ranking is based on DNV RP-F107.

6. The validation analysis of the proposed model is calculated by comparing between number of ships sinking using proposed model and actual data accidents during specific period between 1997 and 2011. The result of the comparison is 0.33 that can be determined as reasonably agreement (ratio $\geq 0.2$ ).

7. In future work, it is important to elaborate the network variable of the Bayesian network to improve the estimation of $P c$ and to develop the mitigation plan to secure subsea pipeline. Mitigation could be performed for the medium- and highfrequency levels by reducing the value of $N a$ or $P c$.

8. To apply the proposed model for deference location, some factors in the Bayesian network can be modified according to the circumstances of a specific location.

Acknowledgment The authors wish to thank Professor Masao Furusho from the Graduate School of Maritime Sciences, Kobe University, for his evaluation of the human performance probability in the Bayesian network model. The authors hereby declare no conflict of interest.

\section{References}

APERC (2000) Natural gas pipeline development in Southeast Asia. Asia Pacific Energy Research Centre report, Tokyo. www.ieej.or.jp/aperc/final/se.pdf. Accessed 16 February 2011

COWI (2008) Risk analysis of sea traffic in the area around Bornholm. Kongens Lyngby, Report No.: P65775-002, Denmark

DNV (2003) Formal safety assessment-large passenger ships, ANNEX II. Det Norske Veritas report No 2003-0277. www.research.dnv.com/skj/ANNEXII.pdf. Accessed 20 March 2011 
DNV (2010) Risk assessment of pipeline protection: recommended practice DNV-RP-F107. Det Norske Veritas, Norway

Fowler TG, Sorgård E (2000) Modeling ship transportation risk. J Risk Anal 20:225-244

Friis-Hansen P, Ravn ES, Engberg PC (2009) Basic modeling principles for prediction of collision and grounding frequencies. The Bassy Toolbox Baltic Sea Safety report Review 3:2009.05.01, Technical University of Denmark

Fujii Y, Yamanouchi H, Mizuki N (1974) Some factors affecting the frequency of accidents in marine traffic: II the probability of stranding and III the effect of darkness on the probability of collision and stranding. J Navig 27:239-249

Goerlandt F, Kujala P (2011) Traffic simulation based on ship collision probability modeling. Reliab Eng Syst Saf 96:91-107

Hänninen M, Kujala P (2012) Influences of variables on ship collision probability in a Bayesian belief network model. Reliab Eng Syst Saf 102:27-40

Harahap RG (2011) Human reliability in ship collision: case study in Tanjung Perak Port Surabaya. Thesis, Institut Teknologi Sepuluh Nopember, Surabaya (in Indonesian)

IMO (2002) Guidelines for the installation of a shipborne automatic identification system (AIS). International Maritime Organization (IMO), London

Kristiansen S (2005) Maritime transportation: safety management and risk analysis. Elsevier ButterworthHeinemann, Oxford, UK, pp 147-148

Kujala P, Hänninen M, Arola T, Ylitalo J (2009) Analysis of the marine traffic safety in the Gulf of Finland. Reliab Eng Syst Saf 94:1349-1357

Montewka J, Hinz T, Kujala P, Matusiak J (2010) Probability modeling of vessel collisions. Reliab Eng Syst Saf 95:573-589

Montewka J, Goerlandt F, Kujala P (2012) Determination of collision criteria and causation factors appropriate to a model for estimating the probability of maritime accidents. J Ocean Eng 40:50-61

Mulyadi Y, Kobayashi E, Wakabayashi N, Zaman MB, Pitana T, Wahyudi (2011) Estimation of pipeline accident probability caused by ship sinking using AIS. Proceeding of International Symposium on Marine Engineering (ISME) D9-3, Kobe, Japan

Otto S, Pedersen PT, Samuelides M (2002) Elements of risk analysis for collision and grounding of a RoRo passenger ferry. J Mar Struct 15:461-474

Pedersen PT (2010) Review and application of ship collision and grounding analysis procedures. J Mar Struct 23:241-262

Pedersen PT \& Zhang S (1999) Collision analysis for MS Dextra. SAFER EURORO Spring meeting paper number 2:1-33, Nantes

Talavera A, Aguasca R, Galvan B, Cacereno A (2013) Application of Dempster-Shafer theory for the quantification and propagation of the uncertainty caused by the use of AIS data. Reliab Eng Syst Saf 111:95-105

Trans Asia Consultants (2009) Trend analysis of sea transportation accidents in 2003-2008. Report for The Indonesia National Transportation Safety Committee. Jakarta (in Indonesian)

Weng J, Meng Q, Qu X (2012) Vessel collision frequency estimation in the Singapore Strait. J Navig 65:207-221 